\section{Does gently clearing the nasal passage affect odor identification?}

\author{
Mitchell G. Spring, Thomas H. Wiseman, \\ Robert M. Hallock
}

Neuroscience Program, Skidmore College, Saratoga Springs, NY, USA

\begin{abstract}
Identifying scents in a wine's bouquet is considered one of the most important steps in the process of wine tasting. An individual's ability to successfully do this is dependent on the sense of smell; thus, altering the nasal microenvironment could have a powerful effect on the wine tasting experience. In the present study, we examined olfactory performance in healthy participants who cleared their nasal cavity before odorant presentations. Fifty undergraduate participants were assessed with a standardized test of olfaction requiring the recognition of a battery of odors. Half of these participants cleared mucus from their nasal cavities (by gently blowing their noses) prior to the assessment. No difference was found in performance between those who cleared their nasal passages and those who did not. Further, data were not different than known population data from the test. These data suggest that gently clearing the nasal cavity before presentation of odorants bears no effect on the ability to perceive those odor qualities.
\end{abstract}

\section{Introduction}

Identifying scents in a wine's bouquet is considered one of the most important steps in the process of wine tasting. ${ }^{1-4}$ An individual's ability to successfully do this is dependent on an intact and functioning olfactory system. Olfaction requires odorants to bind to chemical receptors in the olfactory epithelium, located in the superior portion of the nasal vault. ${ }^{5}$ In order to get to the olfactory epithelium, odor molecules must pass through the nasal airway, which is often narrow, heavily ciliated, and replete with sharp turns. As such, most odorants are caught by the cilia of the nasal mucosa, which line the length of the nasal airways, long before they reach the olfactory epithelium. ${ }^{5}$ The environment of the nasal passage, then, can clearly have a profound effect on the ability to identify odors.

Proper airflow is also crucial for optimal olfaction. ${ }^{6-8}$ At the extreme, a deviated septum, sinusitis, or nasal polyps can prevent proper airflow to the olfactory receptors and lead to anosmia, a lack of the ability to smell. ${ }^{9-14}$ Hornung and colleagues ${ }^{7}$ found that increasing the volume of the nasal passage with a nasal dilator increased an individual's ability to identify odors. This finding presents the possibility that clearing the nasal cavity could also increase olfactory performance.

Wine tasters often clear their nasal cavity before sniffing the aromas of a wine, although the effects of this behavior have yet to be empirically studied. This study sought to examine whether such gentle clearing has an effect on identifying odors.

\section{Materials and Methods}

\section{Participants}

There were 50 students from a small liberal arts college who participated in this study. The age range of these students was between 19 and 22 , and there were 21 male and 29 female participants. Participants were not sick at the time of their sessions, and each was instructed to refrain from eating, drinking, smoking, or chewing gum for at least 30 minutes prior to their session. Smoker status or drug consumption, however, was not assessed. Participants were randomly assigned to either the experimental and control group. Participants received 5 dollars (USD) for their participation.

\section{Materials}

Odor identification was assessed using the Sniffin' Sticks Screening 12 test (Burghart Messtechnik, Wedel, Germany), a standardized test of olfaction. . $^{16}$ This test comprises 12 different odors: banana, cinnamon, clove, coffee, fish, leather, lemon, licorice, orange, peppermint, pineapple, and rose.

Each odor is contained in a separate odor pen; a felt tip that contains an odorant is encased in a hard plastic tube and covered with a plastic cap when not in use. The Screening 12 test includes a set of 12 cue cards, each one corresponding to a separate odor pen. Each card has four separate possible odors that the participant is required to choose from when identifying the scent of each odor stick.

\section{Procedure}

Odor presentation for participants in the control group was as follows: the odor pen was uncapped, and the experimenter, wearing a latex glove, held the felt tip of the pen approximately $2 \mathrm{~cm}$ below the participant's nostrils for 3 to $4 \mathrm{sec}$. During the presentation of the odor, the cue card that corresponded to that odor was presented on a computer screen in front of the participant. Odor identification was done using a forced choice paradigm in which the
Correspondence: Robert M. Hallock, Neuroscience Program, Skidmore College, 815 North Broadway, 12866 Saratoga Springs, NY, USA.

Tel. +1.518.5805740 - Fax: +1.518.5805740.

E-mail: rhallock@skidmore.edu

Key words: odor identification, sniffing, nasal airflow, wine tasting.

Contributions: MS, RH, TW, study design; MS, RH, TW data collection and analyzing; MS, first draft of manuscript; MS, RH, TW, manuscript reviewing and revising.

Conflict of interests: the authors declare no potential conflict of interests.

Acknowledgments: the authors would like to thank Skidmore College for providing funding for this project. Precisely, the work was supported by a Faculty Student Summer Research grant from Skidmore College (Saratoga Springs, NY, USA) to MS and RH, and student opportunity funds to TW.

Received for publication: 30 July 2014

Revision received: 9 October 2014

Accepted for publication: 16 October 2014.

This work is licensed under a Creative Commons Attribution 3.0 License (by-nc 3.0)

() Copyright M.G. Sping et al., 2014

Licensee PAGEPress, Italy

Wine Studies 2014; 3:4625

doi:10.4081/ws.2014.4625

participant was required to choose the name of the odor from the four options displayed on the cue card and record their choice on a response sheet. There was $30 \mathrm{sec}$ before the next trial, and this procedure was then repeated for each of the 12 odor pens. A participant's score was the number of odors that they correctly identified.

Conversely, the procedure for participants in the experimental group was similar, except participants were instructed to clear their nasal cavity by gently blowing their nose into a tissue before each odor presentation.

Performance across the 12 odors was compared between the control and experimental group with a $\chi^{2}$ test for independence, with $\mathrm{P}=0.05$. Additionally, the total number of correctly identified odors for the experimental and control groups were compared using an independent measures $t$-test (alpha $=0.05)$. Further, our data were compared to the $50^{\text {th }}$ percentile of population data provided with the Sniffin' Sticks test. Normative data were given for males and females in different age groups. The performance score of each participant in the present study was matched to the $50^{\text {th }}$ percentile of scores for age and sex matched participants. Then, a matched pairs $t$-test (alpha $=0.05$ ) was used to compare these two 


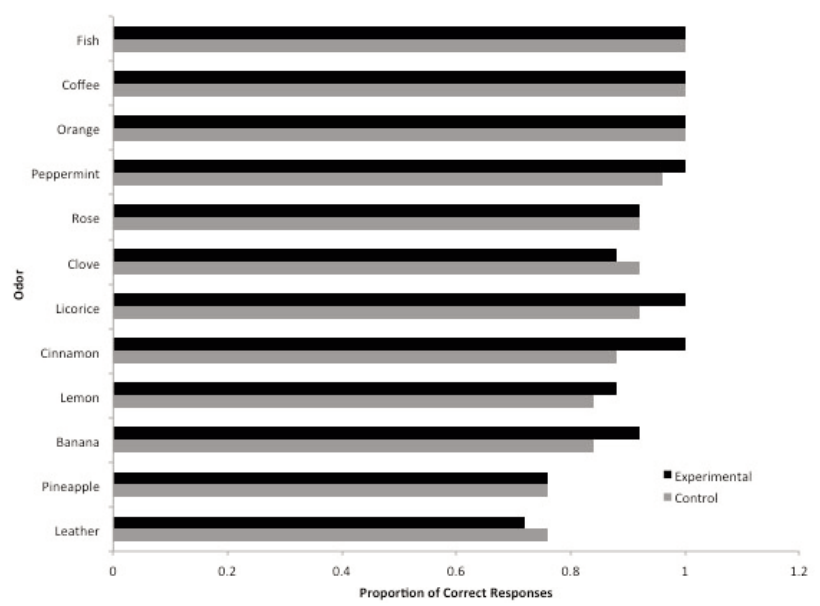

Figure 1. Proportion of correct responses for each individual odor in the experimental and control groups, arranged in descending order by control performance. A chi-square test revealed no significant differences between the two conditions, $\chi^{2}(11)=0.959, P>0.05$.

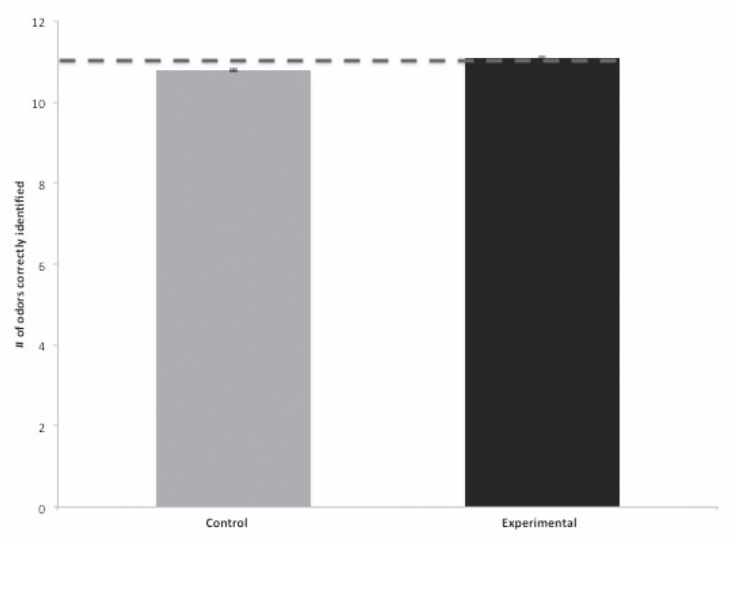

Figure 2. Mean $( \pm$ SEM) number of odors identified by participants in the nasal clearing $(11.08 \pm 0.0297)$ and control groups $(10.8 \pm 0.0367)$. The dashed line indicates the $50^{\text {th }}$ percentile of the population data provided with the test $(M=11)$. No significant difference was observed between the groups, $t(24)=1.09$, $P>0.05$. sets of scores. All protocols were approved by Skidmore College's Participant Review Board (Saratoga Springs, NY, USA).

\section{Results}

The proportion of participants in the control and experimental groups that correctly identified each odor is presented in Figure 1. These proportions were then compared using a chisquare test for independence. This comparison failed to find any significant differences between the groups $\chi^{2}(11, \mathrm{n}=25)=0.959, \mathrm{P}>0.05$.

The number of correct odor identifications between control $(10.8 \pm 0.0367$; mean \pm SEM) and experimental $(11.08 \pm 0.0297$; mean \pm SEM $)$ participants was analyzed with an independent measures t-test (Figure 2). No significant differences were not found between the groups: $t(24)=1.09, P>0.05$. Lastly, participant's scores from the experimental group were paired with population means in the $50^{\text {th }}$ percentile based on the participant's sex and age. This comparison between our participants and the corresponding population data also revealed no significant effect of clearing the nasal passage, $\mathrm{t}(24)=0.464, \mathrm{P}=0.647$. Further, there were no sex differences within our data (data not shown), nor are sex differences present in the population data with this test.

\section{Discussion}

Our experiment showed that gently blowing the nose to clear the nasal passages had no effect on odor recognition in the 12 odors in the Sniffin' Sticks Screening 12 test. This finding demonstrates that the behavior of clearing the nasal cavity before smelling a wine may have no effect on olfactory performance. However, the failure to find an effect could be due to any number of factors. First, the Sniffin' Sticks test we employed in this study may have yielded a ceiling effect, meaning that most participants performed at near maximum levels in both the control and experimental groups. This could allow subtle increases in olfactory abilities to go undetected, because performance on the task was already elevated such that it could not be improved upon. Second, it is possible that clearing the nose did not adequately increase airflow in the right areas. Using a computer model of nasal airflow, Zhao and colleagues $^{17}$ found that the volume of certain areas has a far greater effect on airflow to the olfactory epithelium than others. Thus, if those areas of greater impact were not the ones affected by nasal clearing, an effect would not be expected. Third, the Sniffin' Sticks test measures olfactory recognition abilities using 12 specific odors. Given the nature of this test, it is possible that identification of specific odors that were not assessed may be differentially affected by clearing the nasal passage.

Indeed, the possibility of differential effects for different odors is supported by differences observed between the proportions of correctly identified odors in this study (Figure 1). Graphically, cinnamon appears to present the largest difference between control and experimental participants (Figure 1). No participant in the experimental group incorrectly identi- fied this odor, while three participants in the control group incorrectly identified this odor (though there was no statistical difference in performance between groups). For a number of odors (rose, coffee, fish, pineapple, and orange), however, performance was identical between the two groups. This supports the possibility that our manipulation could have found a difference in identification of an odor that was not tested in the current battery of odors.

\section{Conclusions}

Caveats and potential shortcomings aside, this study was an important first step in testing behaviors that may increase the ability to detect odorants. Although the observed ceiling effect prevents a detailed analysis of differences between groups, further experimental inquiry is warranted. Any method to increase odor sensitivity would have generalizations well beyond the wine community.

\section{References}

1. Robinson J. Jancis Robinson's wine course. New York, NY: Abbeville Press; 1995.

2. Robinson J. How to taste: a guide to enjoying wine. New York, NY: Simon \& Schuster; 2000.

3. Zraly K. Windows on the world complete wine course. New York, NY: Sterling Publ.; 2004. 
4. Grumdahl D. Drink this: wine made simple. New York, NY: Ballantine Books; 2009.

5. Halpern B. Environmental factors affecting chemoreceptors: an overview. Environ Health Persp 1982;44:101-5.

6. Tatchell R, Lerman J, Watt J. Olfactory ability as a function of nasal air-flow volume in laryngectomees. Am J Otolaryng 1985; 6:426-32.

7. Hornung DE, Smith DJ, Kurtz DB, et al. Effect of nasal dilators on nasal structures, sniffing strategies, and olfactory ability. Rhinology 2001;39:84-7.

8. Hilgers FJ, Jansen H, Van As CJ, et al. Long-term results of olfaction rehabilitation using the nasal airflow-inducing ("polite yawning") maneuver after total laryngectomy. Otolaryng Head Neck

\section{2;128:648-54.}

9. Downey L, Jacobs J, Lebowitz R. Anosmia and chronic sinus disease. Otolaryng Head Neck 1996;115:24-8.

10. Mott A, Cain W, Lafreniere D, et al. Topical corticosteroid treatment of anosmia associated with nasal and sinus disease. Otolaryng Head Neck 1997;123:367-72.

11. Kern R. Chronic sinusitis and anosmia: pathologic changes in the olfactory mucosa. Laryngoscope 2000;110:1071-7.

12. Vento S, Ertama L, Hytonen M, et al. Nasal polyposis: clinical course during 20 years. Ann Allerg Asthma Im 2000;85:209-14.

13. Stevens M. Steroid-dependent anosmia. Laryngoscope 2001;111:200-3.

14. Rao J, Kumar E, Babu K, et al. Classification of nasal septal deviations: relation to sinonasal pathology. Indian $\mathrm{J}$ Otolaryng Head Neck 2005;57:199-201.

15. Kobal G, Hummel T, Sekinger B, et al. "Sniffin' sticks": screening of olfactory performance. Rhinology 1996;34:222-6.

16. Hummel T, Kobal G, Gudziol H, MackaySim A. Normative data for the "Sniffin' Sticks" including tests of odor identification, odor discrimination, and olfactory thresholds: an upgrade based on a group of more than 3,000 subjects. Eur Arch OtoRhino-L 2007;264:237-43.

17. Zhao K, Scherer PW, Hajiloo S, Dalton P. Effect of anatomy on human nasal air flow and odorant transport patterns: implications for olfaction. Chem Senses 2004;29:365-79. 